University of Wollongong

Research Online

Faculty of Engineering - Papers (Archive)

Faculty of Engineering and Information

Sciences

2009

\title{
A robust voltage unbalance allocation methodology based on the IEC/TR 61000-3-13 guidelines
}

Prabodha Paranavithana

University of Wollongong, ptp123@uow.edu.au

Sarath Perera

University of Wollongong, sarath@uow.edu.au

Follow this and additional works at: https://ro.uow.edu.au/engpapers

Part of the Engineering Commons

https://ro.uow.edu.au/engpapers/5474

\section{Recommended Citation}

Paranavithana, Prabodha and Perera, Sarath: A robust voltage unbalance allocation methodology based on the IEC/TR 61000-3-13 guidelines 2009.

https://ro.uow.edu.au/engpapers/5474

Research Online is the open access institutional repository for the University of Wollongong. For further information contact the UOW Library: research-pubs@uow.edu.au 


\title{
A Robust Voltage Unbalance Allocation Methodology Based on the IEC/TR 61000-3-13 Guidelines
}

\author{
P. Paranavithana, Student Member, IEEE, and S. Perera, Member, IEEE
}

\begin{abstract}
The International Electrotechnical Commission (IEC) has introduced approaches for managing continuous power quality disturbances (harmonics, flicker and voltage unbalance) in power systems through the allocation of emission limits to customer installations, which are based on a common philosophy. However, it has been found that these harmonics and flicker allocation methods lead to planning levels being exceeded even when no customer exceeds the allocated emission limit. Subsequently, an alternative allocation policy which is referred to as the 'constraint bus voltage' (CBV) method has been developed to overcome this problem. This paper examines the application of the recently introduced IEC voltage unbalance allocation procedure (IEC/TR 61000-3-13) which involves an additional aspect ie. the emission arising from system inherent asymmetries. Paper identifies that this voltage unbalance allocation method also leads to a problem similar to above employing a simple 3-bus test system. A new voltage unbalance allocation policy based on the CBV method is suggested. It is demonstrated that this new voltage unbalance allocation technique satisfies the key allocation objective of complying with the set planning levels.
\end{abstract}

Index Terms - power quality, voltage unbalance, voltage unbalance allocation, IEC/TR 61000-3-13

\section{INTRODUCTION}

The IEC has recently released the Technical Report IEC/TR 61000-3-13 [1] providing guidance for co-ordinating voltage unbalance between various voltage levels of a power system through the allocation of emission limits to unbalanced installations. This is based on a philosophy which is similar to that of the counterpart IEC recommendations for harmonics: IEC 610003-6 [2] and flicker: IEC 61000-3-7 [3] allocation, which involves four key objectives. Firstly, the level of disturbance at any point of any part of the power system should not lead to LV compatibility levels being exceeded. Planning levels in higher voltage parts of the system should be set accordingly. Secondly, the allocation should not distinguish between different types of customer installations, ie. installations of equal MVA demand connected at the same busbar should receive equal emission levels. Thirdly, the allocation should be equitable in some sense, ie. larger installations should be entitled to larger emission levels. Finally, the emission levels should be as large as possible, utilising as much of the network absorption capacity as possible.

Australian standards AS/NZS 61000-3-6 [4] and AS/NZS 61000-3-7 [5] are essentially based on the respective IEC technical reports on harmonics and flicker. Resulting from the difficulties found by Australian utilities in applying these standards, rigorous studies addressing associated deficiencies 978-1-4244-4241-6/09/\$25.00 C2009 IEEE have been carried out (also in progress) at the Integral Energy Power Quality and Reliability Centre, Australia [6], [7]. Arising as a result of these studies, it has been revealed that the application of these standards to even a simple radial network, let alone a relatively complex meshed transmission system, is a highly non-trivial exercise. The IEC harmonics/flicker allocation procedure has been seen to lead to exceedance of a uniform planning level (adopted for a network at a particular voltage level) even when no customer exceeds the allocated emission limit. Employing a simple example, it has been demonstrated in [6] that it is not possible to derive a practical set of emission levels such that all busbars in a transmission network reach a uniform planning level when all emission levels are met. Evidently, a requirement exists for either non-uniform planning levels for various busbars or a more suitable allocation policy. A revised allocation technique for both harmonic and flicker which closely aligns with the IEC guidelines, whereby the emission levels at network busbars are explicitly forced to be at or below the set planning levels when all loads are injecting at their limits derived under the new approach has been introduced. This new technique is known as the 'constraint bus voltage' (CBV) method.

Objectives of this paper are firstly to identify the anticipated problem of exceedence of the set planning levels in relation to the recent IEC/TR 61000-3-13 voltage unbalance allocation approach, and secondly to introduce the suggested CBV allocation policy to overcome this.

This paper is organised as follows: Section II outlines the IEC voltage unbalance allocation procedure. Sections III and IV briefly review the recent work that has been completed addressing two aspects of IEC/TR 61000-3-13: influence coefficients and the global emission from line asymmetries respectively proposing approaches for their evaluation. These will be applied in Section V which examines the application of the IEC allocation policy employing a three-bus test system. Section VI introduces the new CBV allocation policy to voltage unbalance and examines its application. Conclusions are given in Section VII.

\section{IEC Voltage Unbalance Allocation APPROACH [1]}

Principle of the proposed voltage unbalance allocation approach is such that when all connected unbalanced installations are injecting their individual allocations the resultant emission level (in terms of voltage unbalance factor - VUF ) at any 
point in the system should be restricted at or below the set planning level. It is important to note that the aforementioned allocations are derived using the general summation law while taking the contributions from upstream and system inherent asymmetries into account. Based on the above principle the system absorption capacity or the allowed global emission is established as:

$$
U_{g}=\sqrt[\alpha]{\left(L_{k}\right)^{\alpha}-\left(T_{u s-k} L_{u s}\right)^{\alpha}}
$$

where,

$L_{k}, L_{u s^{-}}$planning levels of the system $k$ under assessment and the upstream (US) system respectively

$\alpha$ - summation law exponent

$T_{u s-k}$ - transfer coefficient from the upstream system to the downstream system $k$ under assessment

$U_{g}$ - allowed emission from unbalanced installations and system inherent asymmetries existing in the system $k$ under assessment and the downstream

System absorption capacity $U_{g}$ is apportioned to various busbars (say, $U_{g x}$ for any busbar $x$ ) of the considered system in proportion to the ratio between the total apparent power $S_{x}$ to be supplied by the busbar and the total available apparent power of the entire system $S_{t o t-x}$ as seen at the busbar as:

$$
U_{g x}=U_{g} \sqrt[\alpha]{\frac{S_{x}}{S_{t o t-x}}}
$$

Power $S_{t o t-x}$ is calculated taking into account the voltage unbalance contributions from neighboring busbars $1,2, \ldots, n$ in terms of influence coefficients as:

$$
S_{t o t-x}=k_{1 x} S_{1}+k_{2 x} S_{2}+\ldots+S_{x}+\ldots+k_{n x} S_{n}
$$

where, $k_{i x}$ is the influence coefficient between any busbar $i(i=1,2, \ldots, n$ and $i \neq x)$ and busbar $x$ which is defined as the voltage unbalance caused at busbar $x$ when $1 p u$ of negative sequence voltage source is applied at busbar $i$. Busbar allowance $U_{g x}$ is then apportioned to individual customers (say, $j$ ) connected at busbar $x$ taking into account the global emission from system inherent asymmetries (essentially lines) using the factor $K u e_{x}$ as:

$$
E_{j x}=U_{g x} \sqrt[\alpha]{K u e_{x}\left(\frac{S_{j x}}{S_{x}}\right)}
$$

where,

$$
K^{\prime} u e_{x}=1-K u e_{x}=\left(\frac{U_{\text {lines }-x}}{U_{g x}}\right)^{\alpha}
$$

$E_{j x}$ - emission limit of customer installation $j$ supplied at busbar $x$

$S_{j x}$ - agreed apparent power of customer installation $j$

$U_{\text {lines }-x}$ - emission at busbar $x$ caused by line asymmetries existing in the system under assessment and the downstream system supplied by busbar $x$.

\section{InFLUENCE COEFFiCIENTS [8]}

The Technical Report IEC/TR 61000-3-13 does not provide a systematic approach for deriving influence coefficients. Recent work completed overcomes the above difficulty and proposes a matrix based approach for evaluating influence coefficients $k_{i x}$ between any busbar $x$ and a neighbouring busbar $i$ taking its dependency on the presence of three-phase induction motor loads into account as:

$$
\left[k_{x i}\right]=\left|\left[Y_{++: i j}^{\prime}\right]^{-1}\left[Y_{++: i x}\right]\right|
$$

where,

$Y_{++: i j}^{\prime}=Y_{++: i j}+Y_{--: i-i m}$ for $i=j$

$Y_{++: i j}^{\prime}=Y_{++: i j}$ for $i \neq j$

$i, j=1,2, \ldots, n$ and $i, j \neq x$

Admittance $Y_{++: i j}$ is the $(i, j)^{t h}$ element of the positive sequence nodal admittance matrix. For $i=j, Y_{++: i i}$ is the sum of all network admittances connected to busbar $i$. For $i \neq j, Y_{++: i j}$ is equal to the negative value of the admittance of the network element connecting busbars $i$ and $j$. Admittance $Y_{--: i-i m}$ is the downstream negative admittance seen at busbar $i$ taking into account only induction motors usually supplied by downstream LV systems. Note that this admittance can be approximated to a value of zero if busbar $i$ supplies load bases containing primarily passive loads. Alternatively, when busbar $i$ supplies load bases containing large proportions of induction motors, $Y_{--: i-i m}$ can be expressed in terms of system and load characteristics, system operating conditions and downstream load composition.

\section{FACTOR $K^{\prime} u e$}

The Technical Report IEC/TR 61000-3-13 recommends that system operators determine the factor $K^{\prime} u e$ for their specific networks considering the prevailing line construction practices and system characteristics. However, a systematic methodology for its evaluation is not provided other than a rudimentary direction together with a set of indicative values. Further work shows that the direction given in IEC/TR 610003-13 to assess the influence of an asymmetrical and radial line on the global emission can be applied only when the network supplies primarily passive loads. Presence of induction motors has been seen to have a noticeable influence on the level of emission determined according to the IEC direction. This dependency of the global emission on motor loads can be seen in two forms: (a) local emission or the emission arising from local lines (eg. MV and HV lines when assessing the global emission in MV and HV systems respectively) is influenced by motor loads, (b) in addition, presence of motor loads makes the downstream emission or the emission arising from downstream lines (eg. MV lines when assessing the global emission HV systems) is accountable for the global emission. Overcoming these difficulties a systematic approach, covering radial and interconnected networks, for the evaluation of the global emission caused by line asymmetries at nodal level is developed as:

$$
\left[\left|V_{-: \text {lines }}\right|\right]=\left|\left[Y_{++}^{\prime}\right]^{-1}\left[Y_{-+}^{\prime}\right]\left[V_{+}\right]\right|
$$


where,

$Y_{++i j}^{\prime}=Y_{++}^{i j}+Y_{--}^{i-i m}$ for $i=j$

$Y_{-+i j}^{\prime}=Y_{-+}^{i j}+Y_{-+}^{i}$ for $i=j$

$Y_{++i j}^{\prime}=Y_{++}^{i j}$ for $i \neq j$

$Y_{-+i j}^{\prime}=Y_{-+}^{i j}$ for $i \neq j$

$i, j=1,2, \ldots, n$

Admittances $Y_{++}^{i j}$ and $Y_{--}^{i-i m}$ are as defined for (6). Admittance $Y_{-+}^{i}$ is the downstream negative-positive sequence coupling admittance seen at busbar $i$, which arises as a result of downstream line asymmetries together with the presence of large proportion of motor loads. Thus this admittance is applicable only in assessing the global emission in $\mathrm{HV}$ networks. Voltage vectors $\left[V_{- \text {:lines }}\right]$ and $\left[V_{+}\right]$are the nodal negative sequence (arising due to line asymmetries) and positive sequence voltages respectively. Nodal positive sequence voltage vectors can be considered as known quantities as they can be easily obtained from conventional balanced load flow analysis.

\section{Application OF THE IEC/TR 61000-3-13 ApPROACH TO A THREE-BUS TEST SYSTEM}

\section{A. Test Case Description}

The 3-bus HV network $(66 \mathrm{kV}, 60 \mathrm{~Hz}, 3$-wired) shown in Fig. 1 supplying passive (constant power) loads at all busbars is taken as the test case. Resulting positive sequence system conditions (nodal voltage vectors and line currents) are also indicated in Fig. 1. Relevant admittance data (per km) of the lines are: positive sequence admittance $=(0.6265-j 2.3517) \mathrm{Skm}$, negative-positive sequence coupling admittance when untransposed $=(0.1040+j 0.1779) S k m$.

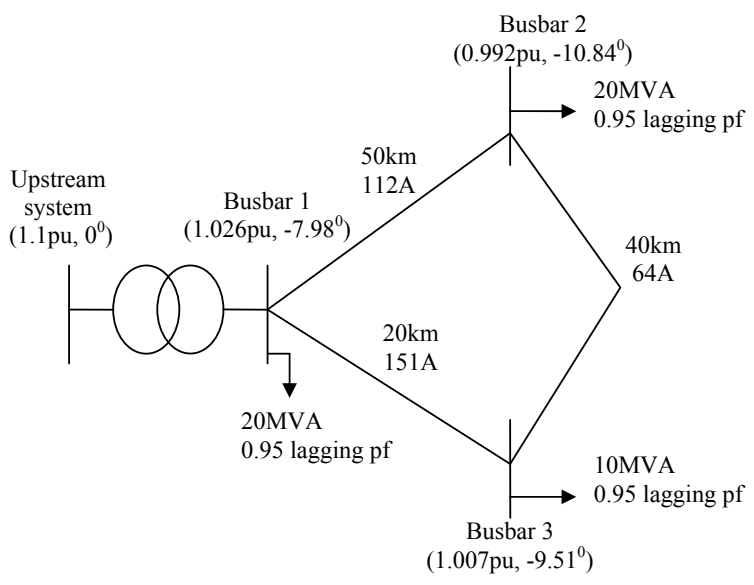

EHV-HV coupling transformer $-230 \mathrm{kV} / 66 \mathrm{kV}, 60 \mathrm{MVA}$, winding resistance $=1 \%$, leakage reactance $=20 \%$, secondary tap setting $=1 \mathrm{pu}$

Fig. 1. 3-bus HV test system

\section{B. Influence Coefficients}

Influence coefficients which are derived using the method stated in Section III (note that $Y_{++i j}^{\prime}=Y_{++i j}$ for $i=$ $j$ and $i \neq j$ as the network supplies passive loads) are given in Table I. Further, a comparison of these influence coefficients with those obtained from unbalanced load flow analysis is given in Fig. 2.

TABLE I

INFLUENCE COEFFICIENTS FOR THE TEST SYSTEM

\begin{tabular}{c|c|c|c|c|c}
\hline$k_{12}$ & $k_{13}$ & $k_{21}$ & $k_{23}$ & $k_{31}$ & $k_{32}$ \\
\hline 1 & 1 & 0.57 & 0.71 & 0.69 & 0.86 \\
\hline
\end{tabular}

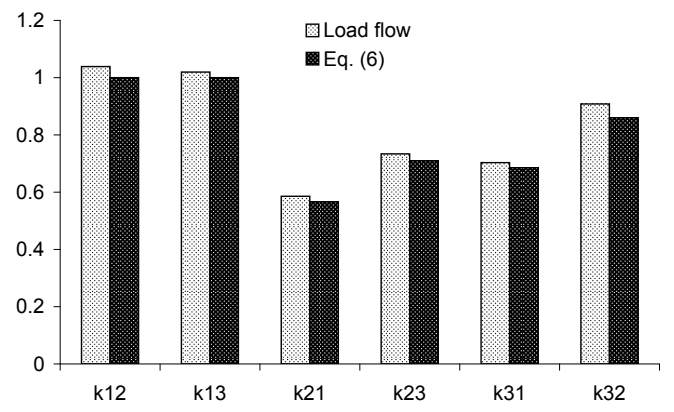

Fig. 2. Comparison of Influence coefficients obtained using (6) and unbalanced load flow analysis

\section{Busbar Allowances}

Power $S_{t o t-x}$ and busbar allocation $U_{g x}$ derived employing (3) and (2) respectively are given in Table II. Zero upstream voltage unbalance contribution and a uniform $\mathrm{HV}$ planning level = 1.4 (indicative value given in IEC/TR 61000-3-13) and a summation exponent $=1.4$ are assumed.

TABLE II

$S_{t o t-x}$ AND $U_{g x}$ FOR THE TEST SYSTEM

\begin{tabular}{c|c|c}
\hline Busbar $(x)$ & $S_{\text {tot }-x}(\mathrm{MVA})$ & $U_{g x}$ \\
\hline \hline 1 & 38.2 & 0.88 \\
\hline 2 & 48.6 & 0.74 \\
\hline 3 & 44.2 & 0.48 \\
\hline
\end{tabular}

\section{D. $K^{\prime}$ ue Factors}

Two cases are considered to demonstrate the application of the IEC/TR 61000-3-13 procedure: (a) Case I - all lines are ideally transposed (ie. $K^{\prime} u e_{x}=0$ for $x=1,2,3$ leading to voltage unbalance allocation formulae which are identical to that used for harmonic/flicker allocation [2], [3]), and (b) Case II - only the line between busbars 1 and 3 is ideally transposed and the other two lines are untransposed. Table III gives the values of the emission $U_{\text {lines }-x}$ derived using the method outlined in Section IV (note that $Y_{++: i j}^{\prime}=$ $Y_{++: i j}$ and $Y_{-+: i j}^{\prime}=Y_{-+: i j}$ for $i=j$ and $i \neq j$ as the network supplies passive loads) and the $K^{\prime} u e_{x}$ factors. A comparison of these factors (for Case II) with those obtained using unbalanced load flow analysis is given in Fig. 3. 
TABLE III

$U_{\text {lines }-x}$ AND $K^{\prime} u e_{x}$ FOR THE TEST SYSTEM (CASE II)

\begin{tabular}{c|c|c}
\hline Busbar $(x)$ & $U_{\text {lines }-x}$ & $K^{\prime} u e_{x}$ \\
\hline \hline 1 & 0 & 0 \\
\hline 2 & 0.39 & 0.41 \\
\hline 3 & 0.05 & 0.04 \\
\hline
\end{tabular}

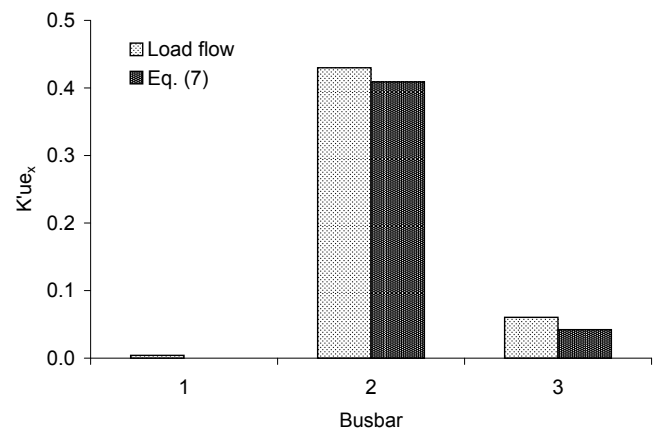

Fig. 3. Comparison of $K^{\prime} u e_{x}$ factors obtained using (7) and unbalanced load flow analysis

\section{E. Emission Limits}

Emission limits $E_{j x}$ (relabelled as $E_{x}$ ), assuming that each busbar supplies a single large load, derived using (4) for the two cases considered above are given in Table IV.

TABLE IV

EMISSION LIMITS FOR THE TEST SYSTEM

\begin{tabular}{c|c|c}
\hline Busbar $(x)$ & $E_{x}$ for Case I & $E_{x}$ for Case II \\
\hline \hline 1 & 0.88 & 0.88 \\
\hline 2 & 0.74 & 0.51 \\
\hline 3 & 0.48 & 0.47 \\
\hline
\end{tabular}

\section{F. Resulting Busbar Emission Levels}

Busbar emission levels $U_{r x}$ when the loads are injecting their allocated limit (Table IV) taking the emission from line asymmetries (Table III) into account can be derived using the general summation law as given by (8). Table $\mathrm{V}$ gives these values for the two cases. Noting that the emission level at busbar 2 exceeds the adopted planning level of 1.4 by approximately $8 \%$ in each case, it can be concluded that the IEC voltage unbalance allocation policy is not robust enough to ensure that the adopted planning levels are not exceeded.

$$
\begin{array}{r}
U_{r x}=\left(\left(k_{1 x} E_{1}\right)^{\alpha}+\left(k_{2 x} E_{2}\right)^{\alpha}+\ldots+\left(E_{x}\right)^{\alpha}+\ldots\right. \\
\left.+\left(k_{n x} E_{n}\right)^{\alpha}+\left(U_{\text {lines }-x}\right)^{\alpha}\right)^{1 / \alpha}
\end{array}
$$

TABLE V

RESULTING BUSBAR EMISSION LEVELS FOR THE TEST SYSTEM

\begin{tabular}{c|c|c}
\hline Busbar $(x)$ & $U_{r x}$ for Case I & $U_{r x}$ for Case II \\
\hline \hline 1 & 1.24 & 1.15 \\
\hline 2 & 1.52 & 1.51 \\
\hline 3 & 1.40 & 1.30 \\
\hline
\end{tabular}

\section{Vi. Constraint Bus Voltage Method for Voltage UnBALANCE ALLOCATION}

A. Constraint Bus Voltage Method (CBV) as Suggested for Harmonics/Flicker Allocation [6]

This new allocation technique derives the emission limit for an installation $j$ connected at a busbar $x$ using:

$$
E_{j x}=k_{a} \sqrt[\alpha]{S_{j x}}
$$

where $k_{a}$ is a proportionality constant which is referred to as the 'allocation constant' that is yet to be determined.

Allocation policy suggested by the IEC gives the emission level $E_{j x}$ as [2], [3]:

$$
E_{j x}=\frac{U_{g}}{\sqrt[\alpha]{S_{t o t-x}}} \sqrt[\alpha]{S_{j x}}
$$

By comparing (9) and (10), the allocation constant $k_{a}$ under the IEC method can be identified as:

$$
k_{a}=\frac{U_{g}}{\sqrt[\alpha]{S_{t o t-x}}}
$$

Note that $k_{a}$ is a bus dependant parameter under the IEC allocation policy as the power $S_{t o t-x}$ is bus dependant.

Simplest way to ensure that busbar emission levels do not exceed the set planning levels is to relax the constraint imposed by (11). Instead, the allocation constant $k_{a}$, making it a global constant, is chosen simply to be the largest value such that:

$$
U_{r x} \leq U_{g} \text { for every bus } x
$$

Resulting emission level $U_{r x}$ at busbar $x$ can be expressed using the general summation law and the individual busbar emission limits $E_{x}$ derived using (9) as:

$$
U_{r x}=k_{a} \sqrt[\alpha]{k_{1 x}^{\alpha} S_{1}+k_{2 x}^{\alpha} S_{2}+\ldots+S_{x}+\ldots+k_{n x}^{\alpha} S_{n}}
$$

Then, $k_{a}$ is established as:

$$
k_{a}=\frac{U_{g}}{\max \left[\sqrt[\alpha]{S_{x}+\sum_{i=1, i \neq x}^{n}\left(k_{i x}^{\alpha} S_{i}\right)}\right]}
$$

In summary, the suggested allocation policy is given by (9) with $k_{a}$ determined using (14). This new policy meets the four key allocation objectives stated in Section I. Firstly, (12) ensures that planning levels are not exceeded when all consumers are injecting their allocated emission levels. Secondly, based on (9) customer installations of equal maximum demand, whether connected at the same or different busbars, receive identical emission levels. Thirdly, (9) ensures that larger loads receive larger emission levels than smaller loads. Finally, the absorption capacity of the network is fully utilised in the sense that at least one busbar is pushed as far as its own planning level is concerned. 


\section{B. Introduction of Constraint Bus Voltage Method to Voltage Unbalance Allocation}

Arising as a result of voltage unbalance due to system inherent asymmetries, the busbar emission allowance $U_{g x}$ (which accounts for both load $S_{x}$ and line asymmetries) and the busbar emission limit $E_{x}$ (associated with load $S_{x}$ ) are not equal to each other as in the case of harmonics and flicker. Thus, the above CBV approach in applying for voltage unbalance allocation requires further modifications.

Extending the allocation policy given by (9), the busbar allowance $U_{g x}$ can be derived as:

$$
U_{g x}=k_{a} \sqrt[\alpha]{S_{x}}
$$

Accounting some headroom in $U_{g x}$ for the emission arising as a result of line asymmetries, the busbar emission limit $E_{x}$ can be established as:

$$
E_{x}=\sqrt[\alpha]{K u e_{x}} U_{g x}=k_{a} \sqrt[\alpha]{K u e_{x} S_{x}}
$$

Resulting emission level $U_{r x}$ at any busbar $x$ can be established using (8) where $E_{x}$ is derived employing (16). Noting that $\left(E_{x}\right)^{\alpha}+\left(U_{\text {lines }-x}\right)^{\alpha}$ in (8) is qual to the busbar emission allowance $U_{g x}$, the resulting emission level $U_{r x}$ under the new allocation method can be expressed as:

$$
\begin{array}{r}
U_{r x}=k_{a}\left(k_{1 x}^{\alpha} K u e_{1} S_{1}+k_{2 x}^{\alpha} K u e_{2} S_{2}+\ldots+\right. \\
\left.S_{x}+\ldots+k_{n x}^{\alpha} K u e_{n} S_{n}\right)^{1 / \alpha}
\end{array}
$$

Then, the allocation constant $k_{a}$, such that the busbar emission constraint $U_{r x} \leq U_{g}$ for every bus $x$ is satisfied and the full system absorption capacity is utilised, can be obtained using:

$$
k_{a}=\frac{U_{g}}{\max \left[\sqrt[\alpha]{S_{x}+\sum_{i=1, i \neq x}^{n}\left(k_{i x}^{\alpha} K u e_{i} S_{i}\right)}\right]}
$$

\section{Application of the Constraint Bus Voltage Method to Volt- age Unbalance Allocation}

Table VI gives the values of the denominator of (18) corresponding to each busbar of the test system shown in Fig. 1. Noting the largest values corresponding to busbar 2 for both Case I and II considered previously, $k_{a}$ values can be derived as given in Table VI.

TABLE VI

VALUES OF $k_{a}$ FOR THE TEST SYSTEM

\begin{tabular}{c|c|c}
\hline Busbar $(x)$ & $\begin{array}{c}\text { Denominator of } \\
(18) \text { for Case I }\end{array}$ & $\begin{array}{c}\text { Denominator of } \\
(18) \text { for Case II }\end{array}$ \\
\hline \hline 1 & 12.65 & 11.61 \\
\hline 2 & 15.90 & 15.82 \\
\hline 3 & 14.53 & 13.27 \\
\hline$k_{a}$ & 0.088 & 0.0885 \\
\hline
\end{tabular}

Busbar emission limits $E_{x}$ as given in Table VII can be derived using (16).

TABLE VII

$E_{x}$ FOR THE TEST SYSTEM UNDER THE CBV METHOD

\begin{tabular}{c|c|c}
\hline Busbar $(x)$ & $E_{x}$ for Case I & $E_{x}$ for Case II \\
\hline \hline 1 & 0.75 & 0.75 \\
\hline 2 & 0.75 & 0.52 \\
\hline 3 & 0.46 & 0.44 \\
\hline
\end{tabular}

Table VIII gives the busbar emission levels $U_{r x}$ derived using (8) while the loads are injecting their allocated limit (Table VII) taking the emissions associated with line asymmetries (Table III) into account. As expected, the CBV method restricts the resulting emission level at the constrained busbar (busbar 2 of the test system) at the allowed global emission level (= 1.4 for the test case) while maintaining the emission levels at other busbars (eg. busbars 1 and 2 of the test system) below the global emission limit.

TABLE VIII

RESULTING BUSBAR EMISSION LEVELS FOR THE TEST SYSTEM UNDER THE CBV METHOD

\begin{tabular}{c|c|c}
\hline Busbar $(x)$ & $U_{r x}$ for Case I & $U_{r x}$ for Case II \\
\hline \hline 1 & 1.11 & 1.03 \\
\hline 2 & 1.40 & 1.40 \\
\hline 3 & 1.28 & 1.18 \\
\hline
\end{tabular}

\section{CONCLUSIONS}

This paper has examined the application of the recently released IEC Technical Report IEC/TR 61000-3-13 in relation to its voltage unbalance allocation procedure. As in the case of the counterpart IEC harmonics and flicker allocation methods, the prescribed voltage unbalance allocation procedure has been also identified to lead to planning levels being exceeded even when no customer exceeds the allocated emission limit. A new voltage unbalance allocation policy based on the suggested constraint bus voltage method has been introduced. This alternative allocation policy has been seen to lead to a robust voltage unbalance procedure which meets the underlying basic principles of the IEC philosophy.

\section{REFERENCES}

[1] "Electromagnetic Compatibility (EMC) - Limits - Assessment of Emission Limits for the Connection of Unbalanced Installations to MV, HV and EHV Power Systems", Technical Report IEC/TR 61000-3-13, Ed. 1, 2008.

[2] "Electromagnetic Compatibility (EMC) - Limits - Assessment of Emission Limits for Distorting Loads in MV and HV Power Systems", Technical Report IEC 61000-3-6, Ed. 1, 1996.

[3] "Electromagnetic Compatibility (EMC) - Limits - Assessment of Emission Limits for Fluctuating Loads in MV and HV Power Systems", Technical Report IEC 61000-3-7, Ed. 1, 1996.

[4] "Electromagnetic Compatibility (EMC) - Limits - Assessment of Emission Limits for Distorting Loads in MV and HV Power Systems", Ausralian/New Zealand Standard AS/NZS 61000-3-6, 2001.

[5] "Electromagnetic Compatibility (EMC) - Limits - Assessment of Emission Limits for Fluctuating Loads in MV and HV Power Systems", Ausralian/New Zealand Standard AS/NZS 61000-3-7, 2001. 
[6] Timothy James Browne, "Harmonic Management in Transmission Networks", PhD thesis, School of Electrical, Computer and Telecommunications Engineering, University of Wollongong, Wollongong, Australia, March 2008.

[7] "Power Quality - Recommendation for the Application of AS/NZS 61000.3.6 and AS/NZS 61000.3.7", Handbook HB 264, Standards Australia/New Zealand, 2003.

[8] Prabodha Paranavithana, Sarath Perera and Robert Koch, "Propagation of Voltage Unbalance in Interconnected Power Systems", accepeted for CIRED 2009, Prague, 8-11 June 2009.

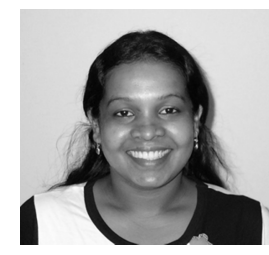

P. Paranavithana (S'2007) received the B.Sc.(Eng) (Hons.) degree in electrical power engineering from the University of Moratuwa, Sri Lanka.

Currently she is pursuing studies towards the $\mathrm{Ph} . \mathrm{D}$. degree at the University of Wollongong, Australia. Her research interests are in power quality and power system analysis.

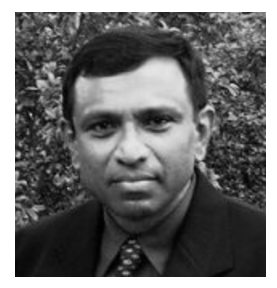

S. Perera (M'1995) received the B.Sc.(Eng) degree in electrical power engineering from the University of Moratuwa, Sri Lanka, a M.Eng.Sc. degree from the University of New South Wales, Australia, and the Ph.D. degree from the University of Wollongong, Australia.

$\mathrm{He}$ has been a lecturer at the University of Moratuwa, Sri Lanka. Currently he is an Associate Professor with the University of Wollongong. He is the Technical Director of the Integral Energy Power Wollongong 